discussed in the first lecture the general principles of the subject, giving illustrations of open-loop and closed-loop systems and outlining the mathematical techniques employed in their analysis. During the discussion the need for improved nomenclature was voiced, and the respective spheres of application of the Laplace transform and Heaviside's operational calculus were discussed.

In the next,lecture, Mr. M. W. Humphrey Davies, of Imperial College, described the action and properties of the several forms of two-stage machines used in rotating amplifiers. In the ensuing discussion attention was directed to the proportionality between the inherent time-constant and power amplification in these machines. Mr. D. Wray, of the English Electric Co., Ltd., spoke next on magnetic amplifiers, giving the outline theory of their action and a review of their principal applications. Their use in push-pull, and dependence on supply voltage, were later discussed. Lecturing on electronic amplifiers, Dr. W. G. Thompson, of the General Electric Co., Ltd., showed how grid control of thyratrons or mercury-arc rectifiers would give flexible control schemes. The advantages and disadvantages of electronic methods were compared, and discussion continued on the different techniques needed with electronic devices, and the need for special training of maintenance staff.

Large D.c. machines, their design limitations and the controls which can be coupled without external amplifiers, were then discussed by Mr. E. P. Hill, of the Metropolitan-Vickers Electrical Co,, Ltd. The effects of iron paths and coupled circuits on timeconstants were treated in the discussion. Mr. A. A. L. Bentall, of the Metropolitan-Vickers Electrical Co., Ltd., followed, illustrating the control of D.C. machines in various combinations with a wide selection of industrial applications. The great flexibility of these machines was emphasized and invoked a varied discussion on their industrial uses. The control of A.C. machines was dealt with by Mr. A. Asbury, of the English Electric Co., Ltd., who outlined the methods of controlling large induction and synchronous motors which find particular application where the largest powers are required. Questions of dynamic braking and unbalanced voltage control were raised in the discussion, during which the smaller A.c. machines also received some consideration.

On September 21 a visit was paid to the Kemsley Paper Mill of the Bowater Lloyd Pulp and Paper Mills, Ltd., where examples of the control of electrical machinery were described and illustrated by $\mathbf{M r}$. A. C. G. Witts and his colleagues of the Bowater organisation. The automatic control schemes for paper machines and wood grinders were of particular interest.

On the concluding day, Mr. W. Spence, of the British Thomson-Houston Co., Ltd., gave a concise summary of the methods of combining control apparatus into a complete closed-loop control system and of assessing the resulting performance. The discussion emphasized the necessity for close collaboration between machine designers, control engineers and users. Mr. A. Asbury dealt finally with the calculation and measurement of the constants of electrical machines and methods for testing a complete control cycle. It was clear from the examples quoted in the discussion that calculated and measured constants are frequently at variance, and methods for reducing the discrepancies were suggested.

The general impression given from the whole course was that rapid progress is being made in the design of control systems and in the appraisal of the relative merits of different schemes. There is still, however, need for a better appreciation by users of the importance of specifying their performance requirements as precisely as possible, and for not asking for a closer control than is really necessary, if they require an economical system.

\section{FINANCIAL INCENTIVES}

$T$ is generally recognized in industry that the provision of adequate incentives for the ordinary worker is one of the ways to improved industrial production. The most obvious and, to some, the most satisfactory form of incentive is more money for better work. For this reason there has been a marked growth of interest in industry, and particularly among the smaller firms, in the introduction of financial incentives schemes. The British Institute of Management has therefore issued a pamphlet describing the most popular wage incentive scheme, methods which have been suggested for introducing and applying them, and elaborating the conditions necessary to their success*.

Before an employer or manager introduces a new financial incentive scheme, it is emphasized that he should first ensure that the tooling, layout, material and finished goods, servicing and general methods of production cannot be improved within the limitations of capital expenditure available. Neither will a new wage incentive system be successful unless good relations exist between management and workers. The scheme should be introduced gradually after effective consultation with the workers, while all supervisors should be informed in the early stages of all details of the scheme. Collective agreements in the industry governing the fixing of basic rates and minimum piecework guarantees should be considered, and rates governing the scheme must cover all possible contingencies.

When the ground has been prepared, the particular scheme to be introduced must be carefully selected, having regard to factors such as the type of production in operation, for example, unit, batch or flow production, the type of labour employed, the grouping of production workers, whether or not skilled time-study operators are available, the probable continuity of supplies, materials and parts, the degree of mechanization of the process and the existing level of earnings of the workers.

Of the wide range of incentive systems which has been evolved the following are representative of the more commonly used.

First is the system of straight piece-work with a guaranteed minimum wage involving the payment of a uniform price for a unit of production; this system is suitable where production is repetitive in character and can easily be divided into similar units. The system has the advantage of being easily understood and earnings are simply calculated.

Secondly, there is the differential piece-work scheme, which is suitable where types of production are similar to those specified for straight piece-work and characterized by similar advantages and limita. tions. In order to enhance the incentive effect of the straight piece-work system some differential piecework schemes include a method whereby the piecework price is increased where normal output in a Management, 1950.) Output. Pp. 66. (London: British Institute of 
given time is surpassed ; these are useful for encouraging the less-skilled worker.

Thirdly, there are the time-saved bonus schemes in which time study is used for setting a standard time, a reward additional to a guaranteed minimum being given to employees who complete the task in less than standard time. Among these are the Gantt method, which provides for the payment of a minimum hourly rate of $66 \cdot 6$ per cent efficiency on the specified. task, at which point the rate begins to increase on a graduated scale. The scheme is useful for machine jobs liable to delay and where expensive machines are operated. Under Emmerson's efficiency method a time is fixed for the job, and the outstanding worker who is able to complete it in this time is regarded as 100 per cent efficient or as representing the unit of efficiency. Where a worker takes longer than the allowed time a calculation of his efficiency is made. For any efficiency in excess of $66 \cdot 6$ per cent (which represents the minimum time-rate) a bonus is paid on a sliding scale, yielding 10 per cent bonus on 90 per cent efficiency. The scheme is useful for gradual transition from day-work to a high-incentive piecework plan.

Schemes of a similar nature include the Halsey system, the Rowan system and the standard hour plan.

Fourthly, there is the point system, which introduces a new element into wage incentive systems. In place of task times and production units, the point system evaluates a piece of work in time units which purport to take account of the amount of skill and energy required for its efficient performance and also for the amount of rest an average worker needs during its performance. In one scheme, for example, the unit of one minute represents the expenditure of energy plus allowance for recovery, there being sixty units in an hour. The number of units represented by each operation must be determined by work study, and this inevitably involves the employment of skilled work-study engineers. The plan is somewhat more expensive to install and administer than other schemes, and may prove complicated and difficult for workers to understand.

The payment systems already described relate the award to the effort of the individual worker. There are, however, many situations in industry where work is carried out by teams in which the individual efforts of each worker are conditioned by the efforts of the other members of the team. To meet such situations, many forms of group incentives have been devised. The major problem is to devise a method of distributing group incentive payments that will be acceptable to all the members of the group. The Priestman bonus scheme is one of the more common group incentive schemes which are used in Britain. It is based on the principle that, if a given number of men in a given time, when working under ordinary methods and at day-rate, are capable of producing a certain quantity and type of finished goods (called the standard output) then, if by greater collective effort without increasing the number of men or their hours of working the workers can increase this output, a percentage is added to their day-rate equivalent to that by which the standard output has been increased. Group incentive schemes have three main applications in which they may be superior to individual piece-work systems :

(1) Conveyor-work where operators cannot produce any more work than is passed to them by the operators preceding them on the line of production.
(2) Work other than on conveyor where quality and handling of an operation can greatly affect the subsequent operation.

(3) Work of such a varied nature, both as to kind and quantity, as to make individual measurement impracticable or excessively expensive.

There is, however, a growing number of people in industrial management which holds that for several reasons, payment-by-result schemes, whether individual or group, fail to exercise the maximum possible overall incentive effect. It is wrong, they argue, that all reward should be directed only towards the quantity of work produced. There are many other qualities which go to make the best type of worker which may be overiooked if quantity of work is to be the sole criterion of an efficient employee.

For these reasons, in recent years, a few undertakings have been seeking for a more equitable and acceptable basis of payment. One method which is winning growing recognition and adoption is the individual assessment bonus scheme. This starts with an arrangement to pay to every worker as a minimum the time-rates fixed by collective agreement in the industry. To this is added a sum which is based on a very careful assessment of each worker in respect of a number of qualities displayed by him. The qualities assessed will probably include regular attendance at work, punctual starting, saving of time, quantity of work as observed over the review period of three or six months, team work and co-operation with colleagues and supervision, personal conduct, care of the company's equipment and tools, general ability and aptitude, saving of materials and quality of work. Each of the qualities selected is allotted a number of points, these being weighted in accordance with their importance. The scheme presents a simple means of sharing with employees increased prosperity arising from improved performance.

Great care should be taken in selection of the incentive scheme to suit the particular type of production, and the booklet gives examples of schemes which might be suitable for different types of industries. Before any incentive scheme is contemplated it should be made clear that the object of incentive payment is to encourage the worker to produce his maximum output without undue fatigue.

T. H. HAwkINS

\section{EXPERIMENTAL AND RESEARCH STATION, CHESHUNT}

\section{ANNUAL REPORT FOR 1948}

COMMERCIAL horticulture under glass is expanding steadily, and, in spite of the growing contribution to food supplies, such intensive cultivation brings problems of culture, nutrition and disease. The annual report for 1948 of the Experimental and Research Station, Cheshunt, Herts*, shows how the work of the Station has increased the yield of tomatoes and lettuce. Its recent trials indicate that the English tomato Downes Seedling and the Dutch variety Bruinsma gave the highest yields, at 61 tons per acre. The new Cheshunt $5 B$ lettuce matures eight days earlier than the Station's original intro. duction, Early Giant. Mushrooms grown on horse

* Experimental and Research Station, Cheshunt. Annual Report (Thirty-fourth Year), 1948. Pp. 90+4 plates. (Cheshunt: Nursery 